\title{
Application of Mobile Mechanical Arm in Curtain Wall Installation of Xinhua Star
}

\author{
Li Fenghui, Che Zhiyan*, He Wei \\ China Construction Shenzhen Decoration Co., Ltd. Shenzhen, China
}

Email address:

7959025@qq.com (Che Zhiyan)

${ }^{*}$ Corresponding author

\section{To cite this article:}

Li Fenghui, Che Zhiyan, He Wei. Application of Mobile Mechanical Arm in Curtain Wall Installation of Xinhua Star. Engineering and Applied Sciences. Vol. 4, No. 5, 2019, pp. 118-122. doi: 10.11648/j.eas.20190405.15

Received: August 2, 2019; Accepted: September 18, 2019; Published: September 30, 2019

\begin{abstract}
Chengdu Xinhua Star Project is designed by integrating insert unit elements with aluminum panel boxed eave. Because the unit elements are installed between the upper and lower floors, the traditional vertical lifting process cannot meet the installation requirements. Therefore, this project uses the mobile mechanical arm developed by our company for installing unit element indoors. The mobile mechanical arm is $3045 \times 1699 \times 1320 \mathrm{~mm}$ with the rated load of $600 \mathrm{~kg}$, the self-weight of $1750 \mathrm{~kg}$ and the counterweight of $600 \mathrm{~kg}$. It can be disassembled or separate transportation and has the functions of free displacement, three-dimensional adjustment and absorption and grabbing. During construction on site, first of all, the grid lines, finished surface line, and bottom and top locating lines of the adapting piece of the unit element are clearly marked and set out on the main structure. According to the geometric dimension of the mechanical arm and the locating line of the curtain wall, the movement locating line of the mechanical arm is drawn. Then, the mechanical arm is operated indoors for installation. The indoor installation process of curtain wall explored by this project provides a new idea for the construction of the unitized curtain wall of ultra-high rise buildings. It can alleviate the construction difficulty of the unitized curtain wall, reduce the safety risks and measure costs of outdoor installation of the unitized curtain wall of ultra-high rise buildings, thus being a new type of curtain wall construction process that is worthy of promotion and application.
\end{abstract}

Keywords: Insert Unitized Elements, Mechanical Arm, Electric Chuck

\section{Background of Mobile Mechanical Arm}

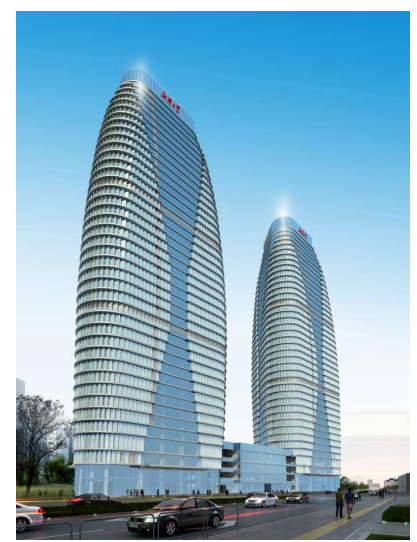

Figure 1. The architectural effect of the project.
Chengdu Xinhua Star Project is located in Jinjiang District, Chengdu. With the "mountain of books" as the skeleton, decorating by "bamboo slips" and forming an image of "lighthouse" on the whole, this project symbolizes "heights of culture, a beacon of industry". The size change echoes the regional urban design requirements and the shape narrows in the vertical direction so that the entire tower shape is more beautiful and it will become a new landmark in the south of Chengdu.

The curtain wall of this project is designed by integrating insert unit elements with aluminum panel boxed eave. Because the unit elements are installed between the upper and lower floors, a single vertical lifting tool cannot meet the installation requirements and auxiliary measures must be taken indoors so that the unit element can move indoors and be installed [1]. The mobile mechanical arm is proper for application under such circumstance. 


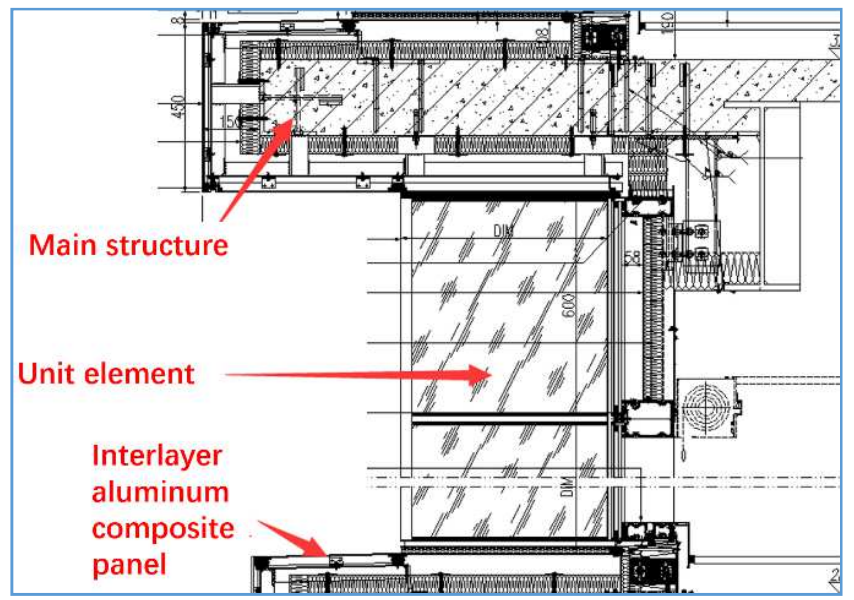

Figure 2. Installation nodes of unit elements.

\section{Research Status and Significance of Applying Mobile Mechanical Arm in the Installation of Curtain Walls}

Through the novelty search and market survey, the relevant research contents of applying the mechanical arm in the installation of curtain walls have not been found yet at home and abroad.

With the advancement of urbanization, the urban construction land is being gradually reduced and the buildings are transforming from the original massive volume to be the super high rise, and the elevation of landmark buildings in cities ceaselessly reach new heights in the sky. The unitized curtain wall construction of super high-rise buildings faces very high safety risks [2]. Moreover, the construction is subject to many constraints by the main structure. Because it is difficult to lift and install unitized curtain walls in the existing super high-rise buildings and the installation is conducted outdoors, there are too many safety hazards [3], so the existing installation scheme must be innovated.

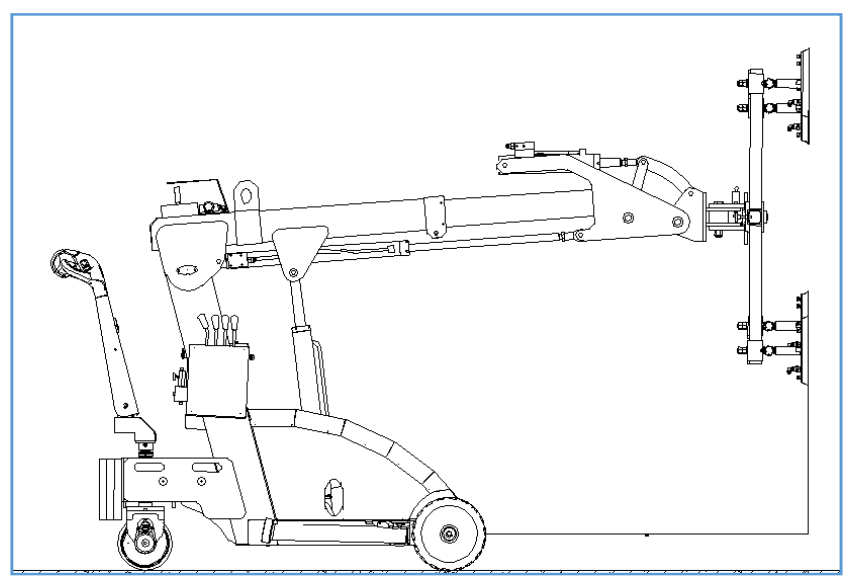

Figure 3. Schematic of mobile mechanical arm.

The research proposes an indoor installation technique for unitized curtain walls in super high rise buildings, which can not only meet the need for Xinhua Star Project, but also provide a new method or new idea to solve problems that cannot be solved by other installation techniques. This research explores the indoor installation technique for unitized curtain walls in super high-rise buildings, decrease the difficulty for work by developing the considerate indoor installation technique and reduce the safety risks and measure costs of outdoor installation of curtain walls for super high-rise buildings, as well as the influence of constraints by the main structure.

Applying the research results in practical construction can achieve good economic and social benefits, such as shortening the construction period, increase of accuracy, reduction of the workload of designers, and ensuring safety of constructors.

\section{Study of Mobile Mechanical Arm}

The mechanical arm suitable for the curtain wall installation should include at least the following functions: free displacement, three-dimensional regulation and grab and lift. The technology of the mechanical arm is researched with the aid of the structural calculation results by the professional devices [4]. First, the project department conducts the field survey and measurement and completes the feasibility analysis [5]. Then the mechanical arm is developed and produced, and finally the improvement and technical summary are made [6].

Free displacement: The flexible movement and walk are realized by tires and the console behind it.

Three-dimensional regulation: The mechanical arm has functions such as surge, pitch, up and down heave, left and right sway, and lateral yaw. The maximum extension distance of the telescopic arm is 1.2 meters, and the maximum angle of elevation is $60^{\circ}$. The front chuck holder can complete $50 \mathrm{~mm}$ up and down heave, $50 \mathrm{~mm}$ horizontal sway, up and down $180^{\circ}$ yaw, and left and right $180^{\circ}$ yaw [7].

Grab and lift: The chuck mechanical arm can grab and release the unitized element. Through calculation and measurement, its rated grab weight is $600 \mathrm{~kg}$, and the maximum lighting weight of 6 chucks of the mechanical arm is $1,947 \mathrm{~kg}$, about 3.25 [8] times of the rated lifting capacity.

The entire mobile mechanical arm is composed of a drive system, a mechanical system, a hydraulic system, a chuck holder system and a control system.

The drive system includes the frame and the wheel to realize the flexible movement and walk of the mechanical arm, without the need for the assembly and disassembly process when the mechanical arm is being moved, thus it can save time and improve the construction efficiency.

The mechanical system comprises a telescopic arm connected to the frame, an up-and-down reverse arm hinged at the front end of the telescopic arm, and left-and-right reverse arm hinged at the front end of the up-and-down reverse arm. The front and rear distance are regulated during the installation process by connecting the telescopic arm through the frame and connecting the electric chuck holder to the front end of the telescopic arm.

The hydraulic system consists of 5 groups of hydraulic 
jacks: the 1st group is vertically connected between the telescopic arm and the frame to control the pitch of the telescopic arm; the 2nd group is connected to the telescopic arm to control the surge of the telescopic arm; the 3rd group is connected between the telescopic arm and the up-and-down reverse arm to control the up and down yaw; the 4th group is connected between the telescopic arm and the left-and-right reverse arm to control the left and right yaw; and the 5th group is connected between the left-and-right reverse arm and the electric chuck holder to work together with the coupling link rod to control the left and right sway of the electric chuck holder.

The chuck holder system has one electric chuck holder and 4 to 8 vacuum chucks evenly distributed on the electric chuck holder. The movement and installation operations are carried out mainly by grabbing the unitized element with the chucks.

The control system includes one control handle and one control line. The control handle has an inductive control function. The magnitude of the operating force determines the speed of response of the mechanical arm. The control panel is operated to realize the automatic installation of the unitized element. Only by operating the control handle on the indoor floor, we achieve the adjustment in place and subsequent installation of the unutilized elements.

\section{Use of Mobile Mechanical Arm}

Step 1: Accurately measure and set out according to the curtain wall construction drawings, and obviously mark and set out the grid lines, finished surface line, and bottom and top locating lines of the adapting piece of the unit element on the main structure [9];

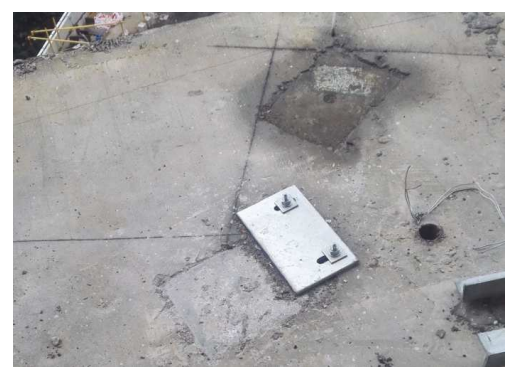

Figure 4. Setting-out of finished surface for curtain wall installation.

Step 2: According to the relationship between the geometric dimension of the mechanical arm and the grids of the unit element, measure the locating line for installation by the mechanical arm, and visibly mark and set out it on the main structure, so as to improve the locating efficiency for installation by the mechanical arm [10];

Step 3: Install the bottom section adapting system of the unit element based on the measurement and setting-out results;

Step 4: Install the bottom section of the unit element on each floor according to the construction drawings;

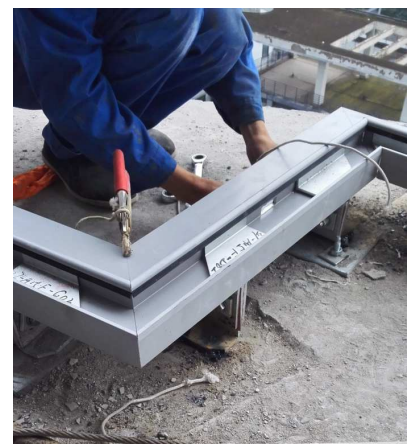

Figure 5. Installation of bottom section.

Step 5: Install the top adapting system of the unit element based on the measurement and setting-out results;

Step 7: Locate the mechanical arm for installing the unit element pursuant to the locating line marked during measurement and setting-out;

Step 8: The vertical lifting equipment is used to lift the unit element to the outer side of the corresponding floor;
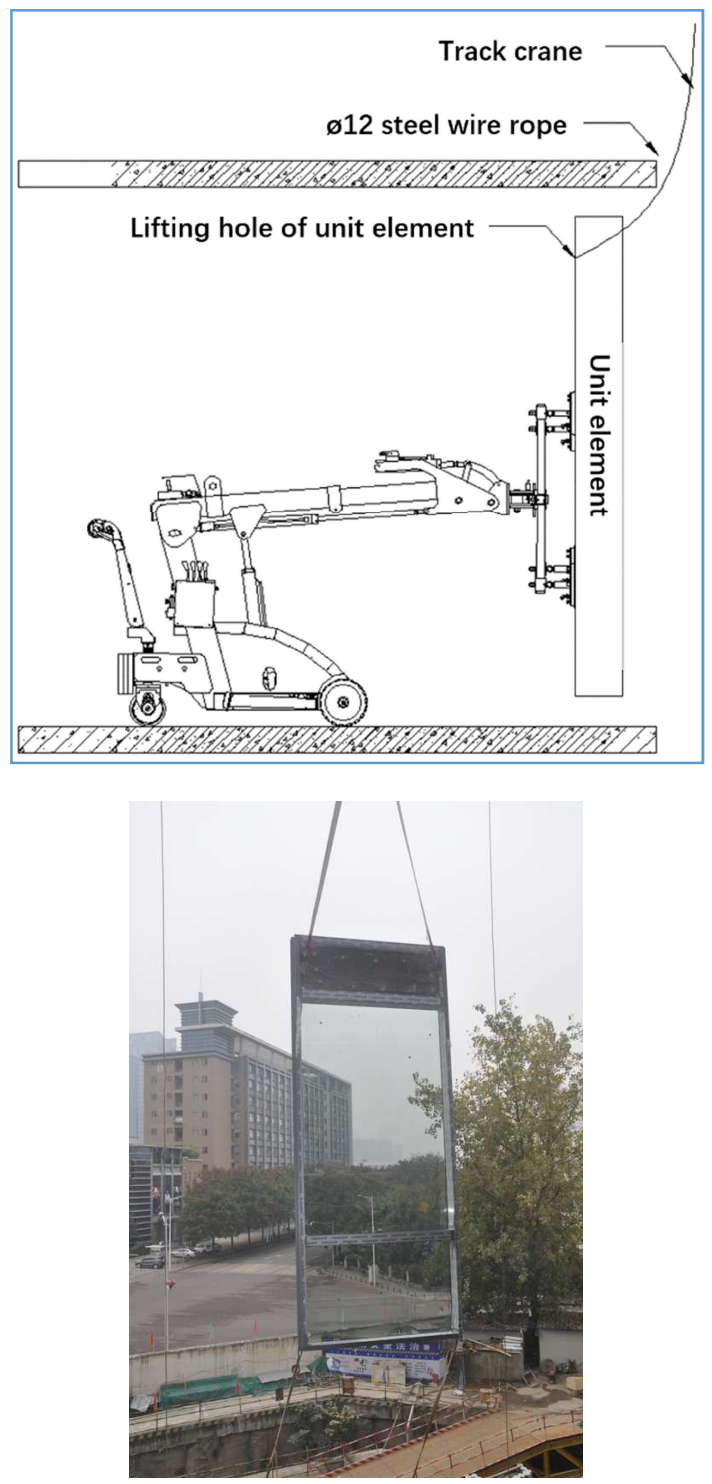

Figure 6. Transportation of unit element to the installation area. 
Step 9: Operate the control handle to grab the unit element by the electric vacuum chuck on the front end of the mechanical arm;

Step 10: Operate the control handle to complete the locating of unit element and then the unit element is temporarily fixed by bolts;

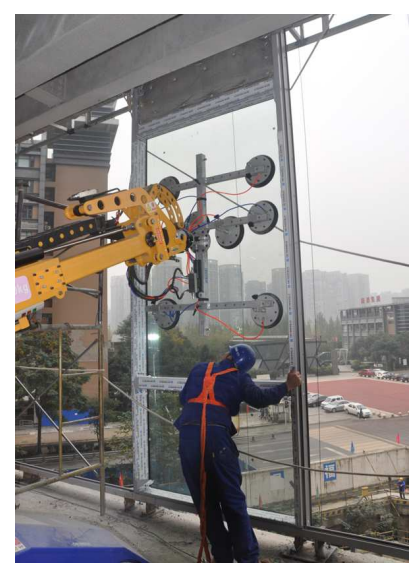

Figure 7. Location of unit element.

Step 11: Slightly adjust the unit element for locating, connect and fasten unit element and its top adapting piece by bolts, remove the mechanical connection between the unit element and the mechanical arm, and then the unit element installation is completed.

\section{Safety Performance Analysis of Mobile Mechanical Arm}

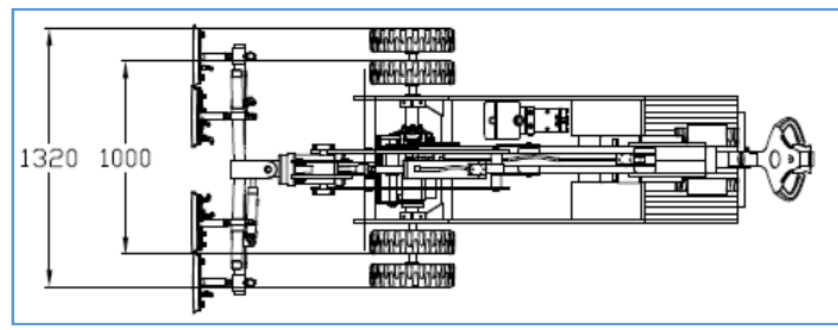

Figure 8. Top view of mechanical arm.

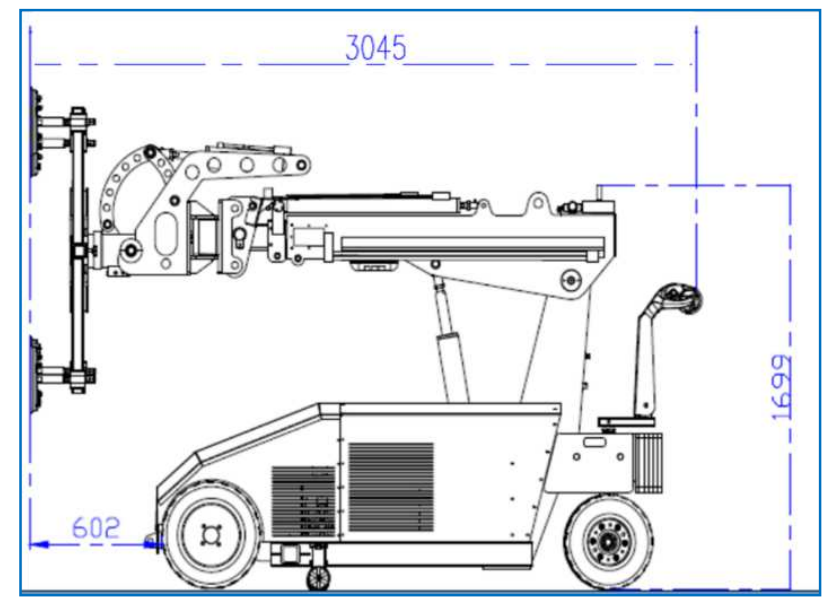

Figure 9. Lateral view of mechanical arm.
1) Safety of transportation

The outline size of the mobile mechanical arm is $3045 \times 1699 \times 1320 \mathrm{~mm}$ [11] and its self-weight is $1750 \mathrm{~kg}$, including a counterweight of $600 \mathrm{~kg}$, which may be transported separately after being dismantled. Therefore, the conventional elevators at the construction site may meet its transportation requirements.

2) Safety of use

The rated load of the mechanical arm is $600 \mathrm{~kg}$. The self-weight of a conventional unit element of Xinhua Star Curtain Wall Project is $395 \mathrm{~kg}$, and the weight of a maximum unit element is $551 \mathrm{~kg}$. The load of the mechanical arm is able to lift up unit elements of such weight. Meanwhile, during lifting, a vertical steel wire rope is used as a fall-proof rope to ensure safety and controllability of the construction process.

The electric chuck at the front end of the mechanical arm adopts a dual vacuum system to ensure that the grabbing capability of the electric chuck meets the design requirements [12].

\section{Economic Analysis of Mobile Mechanical Arm}

With five groups of hydraulic cylinders, the mechanical arm for installing unit elements can achieve the in-out expansion and contraction of the mechanical arm, expansion and contraction at high and low positions, $180^{\circ}$ left and right turnover of vacuum chuck rack, $180^{\circ}$ upper and lower turnover of vacuum chuck rack as well as horizontal displacement of $50 \mathrm{~mm}$ towards left and right of vacuum chuck rack [13], thus satisfying the need for three-dimensional adjustment while unit elements are being installed. The mechanical arm is driven by the front wheel at the bottom of the vehicle frame, and the rear wheel controls the direction to realize the flexible movement and walking of the mechanical arm. According to the relationship between the geometric dimension of the mechanical arm and the grids of the unit element, the locating line for installation by the mechanical arm is measured, and visibly marked and set out on the main structure, so as to improve locating efficiency for installation by the mechanical arm [14]. The installation efficiency of the entire curtain wall is ensured by accurate measurement and setting-out. The mechanical arm can realize the indoor automated installation of unit elements and enhance the construction safety of super high-rise unitized curtain wall [15]. The entire construction is simple, easy for operation, safe and greatly reducing the labor intensity. Currently, more than 7,000 pieces of unit elements of the exemplary wall of Chengdu Xinhua Star Project have been installed with the mobile mechanical arm. Moreover, the convenience and safety of the mobile mechanical arm in construction are recognized by all parties and the cost reduction and efficiency increase are also very obvious. 


\section{Conclusions}

The curtain wall installation technology by the mobile mechanical arm, as a new process, can overcome the difficulty in installing the façade entrance/exit position of the curtain wall in the project. Compared with the traditional curtain wall lifting technology, the mobile mechanical arm can solve the process of installing the unitized curtain wall in complicated façade with more flexible and quick construction measures and lower construction cost. In contrast with other construction method, the mobile mechanical arm can move the work at heights indoors, reduce the safety risks during construction and become safer.

The curtain wall installation technology by the mobile mechanical arm can provide a new solution for the future unitized curtain wall construction.

\section{References}

[1] JGJ160-2016, Technical code for inspection of machinery and equipment on construction site [S]. Beijing: China Architecture \& Building Press, 2016.

[2] JGJ59-2011, Standard for construction safety inspection [S]. Beijing: China Architecture \& Building Press, 2011.

[3] JGJ80-2016, Technical code for safety of working at height of building construction [S]. China Planning Press, 2016.

[4] GB50786-2012, Standard for building electricity drawings [S]. Beijing: China Architecture \& Building Press, 2012.

[5] GB25295-2010, Guidelines on safety designs for electric equipment [S]. Beijing: Standards Press of China, 2010.
[6] GB/T17852-2018, Geometrical product specifications (GPS) — Geometrical tolerancing —Profile tolerancing [S]. Beijing: Standards Press of China, 2018.

[7] JGJ/T324-2014, Standard for test method of building curtain wall engineering [S]. Beijing: China Architecture \& Building Press, 2014.

[8] GB50009-2012, Load code for the design of building structures [S]. Beijing: China Architecture \& Building Press, 2012.

[9] GB/T21086-2007, Curtain wall for building [S]. Beijing: Standards Press of China, 2007.

[10] GB/T 19740-2005, Mechanical vibration and shock- Free mechanical impedance of the human hand-arm system at the driving point [S]. Beijing: Standards Press of China, 2005.

[11] GB/T 1182-2018, Geometrical product specifications (GPS) - Geometrical tolerancing - Tolerance of form, orientation, location and run-out [S]. Beijing: Standards Press of China, 2018.

[12] GB/T 9414.2-2012, Maintainability of equipment - Part 2: Maintainability requirements and studies during the design and development phase [S]. Beijing: Standards Press of China, 2013.

[13] Wen Bangchun. Machine Design Handbook Vol. 5 Electro-mechanical Integration and Control Technique [M]. China Machine Press, 2010: 1072.

[14] Gao Wei, Yang Zhongping and Zhao Rongfei. Optimum structure design of mechanical arm [J]. Machinery Design and Manufacture, 2006 (01): 14-16.

[15] Xiong Xingming and Cao Caikai. PLC Control of an Industry Manipulator [J]. Control \& Automation, 2006 (31): 127-129. 